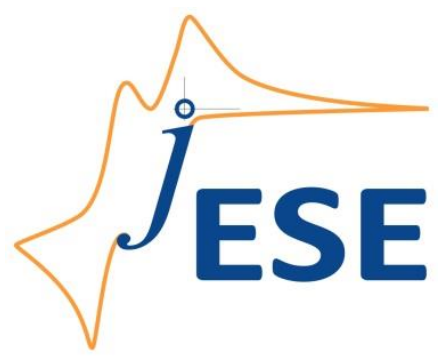

Open Access : : ISSN 1847-9286

www.jESE-online.org

Original scientific paper

\title{
Use of hydrous titanium dioxide as potential sorbent for the removal of manganese from water
}

\author{
Ramakrishnan Kamaraj, Pandian Ganesan and Subramanyan Vasudevan ${ }^{\bowtie}$ \\ CSIR-Central Electrochemical Research Institute, Karaikudi - 630 006, India
}

${ }^{\square}$ Corresponding Author E-mail: vasudevan65@gmail.com; Tel.: +91-4565-241278

Received: October 4, 2014; Revised: October 30, 2014; Published: MMMM DD, YYYY

\begin{abstract}
This research article deals with an electrosynthesis of hydrous titanium dioxide by anodic dissolution of titanium sacrificial anodes and their application for the adsorption of manganese from aqueous solution. Titanium sheet was used as the sacrificial anode and galvanized iron sheet was used as the cathode. The optimization of different experimental parameters like initial ion concentration, current density, $\mathrm{pH}$, temperature, etc., on the removal efficiency of manganese was carried out. The maximum removal efficiency of $97.55 \%$ was achieved at a current density of $0.08 \mathrm{~A} \mathrm{dm}^{-2}$ and $\mathrm{pH}$ of 7.0. The Langmuir, Freundlich and Redlich Peterson isotherm models were applied to describe the equilibrium isotherms and the isotherm constants were determined. The adsorption of manganese preferably followed the Langmuir adsorption isotherm. The adsorption kinetics was modelled by first-and second-order rate models and the adsorption kinetic studies showed that the adsorption of manganese was best described using the secondorder kinetic model. Thermodynamic parameters indicate that the adsorption of manganese on hydrous titanium dioxide was feasible, spontaneous and exothermic.
\end{abstract}

Keywords:

Titanium dioxide; manganese; adsorption; thermodynamics; isotherm; kinetics.

\section{Introduction}

Manganese $(\mathrm{Mn})$ is a naturally occurring element found in the air, soil, and water. It can exist in seven oxidation states ranging from -2 to +7 . It is rarely found in its elemental state and is therefore a component of over 100 minerals and exists mainly as oxides, carbonates, and silicates. Its most common mineral is pyrolusite $\left(\mathrm{MnO}_{2}\right)$. In ground water, manganese is a common contaminant and its presence is due to leaching processes and varies widely depending on the rock type. Also, manganese has a variety of applications such as in ceramics, metallurgical 
processes, mining, dry cell batteries, pigments and paints which all can be the sources of underground pollution [1]. In addition to the disposal of untreated discharge from above the applications into water, another major source of pollution of the manganese is burning of coal and oil [2]. Manganese is an essential metal for the human system and many enzymes are activated by manganese. The manganese contaminant in ground water affects the intelligent quotient (IQ) of children. Intake of higher concentrations of manganese causes neuro toxic disease like Parkinsonism and manganese psychosis, an irreversible neurological disorder [3-5]. The prolonged over intake potentially affects the central nervous system, lungs, also causes diseases of disturbed speech called prognosis, also cause bronchitis and pneumonia [6,7]. The World Health Organization (WHO) prescribed the permissible limit for the manganese in the ground water is $0.05 \mathrm{mg} \mathrm{L}^{-1}$. For this reason, there is great interest in the development of environmentally clean methods to destroy such compounds in aqueous medium for avoiding their dangerous accumulation in the aquatic environment.

Because of its high solubility over a wide $\mathrm{pH}$ range, toxicity and non-degradable nature, it is notoriously difficult to remove manganese from contaminated water $[8,9]$. Hence the researchers in the world have carried out significant work on their removal from aqueous solutions and industrial effluents [10-16]. The usual method for removing toxic metals from water include electrodialysis, chemical coagulation, reverse osmosis, co-precipitation, complexation, solvent extraction, ion exchange, electrochemical treatment and adsorption. Physical methods like ion exchange, reverse osmosis and electrodialysis have proven to be either too expensive or inefficient to remove manganese from water. At present, chemical treatments are not used due to disadvantages like high costs of maintenance, problems of sludge handling and its disposal, and neutralization of effluent. In this scenario, the electrochemical technologies have received great attention for the prevention of pollution problems, as reported in several reviews [17-19].

In the recent decade, electrodissolution process, where the coagulants generated in-situ, has been increasingly used in the world for treating the industrial wastewater, ground water and surface water and many studies conducted to optimize this process for specific problems [19]. The sacrificial anodic electrodes, commonly consisting of iron and aluminum, are used to continuously supply metallic ions as the source of coagulants, which can hydrolyze near the anode to form a series of metallic hydroxides capable of destabilizing dispersed particles. This process generates large quantities of iron and aluminum salt coagulated sludge, which inhibits efficient water treatment. From the generated coagulant, nothing may be recovered or reused, and require further incineration and landfill treatment. Furthermore, the appearance of dissolved iron in aquatic suspensions can lead to visual, odor and taste problems resulting from later growth of iron bacteria [20]. Even aluminum salts are suspected to be harmful to human and living things [21]. Consequently, a coagulant that is safer and produces more reusable coagulated sludge could offer a novel solution to many environmental and economic problems associated with sludge handling. However, reports on novel electrodes materials remain very scarce in the literature for the generation of reusable and environmentally friendly coagulant. Removal of metal contaminants by the chemically synthesized, different forms of, titanium dioxide was widely reported [22-25] and was similar to that of the most widely used iron and aluminum salt flocculation. Furthermore, long-term toxicological studies have not found titanium salt in water to have any adverse effects. All the above factors suggest that the titanium salt can be used as an alternative coagulant [26].

In this investigation, titanium was used instead of iron and aluminum as a novel alternative sacrificial anode, and the removal of manganese from water by titanium-based electrocoagulation 
was investigated. To optimize the maximum removal efficiency of manganese, different parameters like current density, $\mathrm{pH}$, and temperature, inter electrode distance and co-existing ions were studied. In doing so, the equilibrium adsorption behavior is analyzed by fitting models of Langmuir, Freundlich and Redlich Peterson. The adsorption kinetics was modeled by first- and second- order rate models. Activation energy is evaluated to study the nature of adsorption.

\section{Experimental}

\section{Chemicals}

Manganese nitrate $\left[\mathrm{Mn}\left(\mathrm{NO}_{3}\right)_{2}\right]$ of analytical grade was purchased from MERCK. Hydrochloric acid $(\mathrm{HCl})$ and sodium hydroxide $(\mathrm{NaOH})$ used for $\mathrm{pH}$ adjustment were of analytical grade from MERCK. Sodium chloride ( $\mathrm{NaCl}$ ) used for better conductivity of electrolyte of analytical grade from MERCK. Sodium phosphate, sodium silicate, sodium carbonate and sodium fluoride used as coexisting ions were of analytical grade and purchased from MERCK.

\section{Electrolytic system and electrolysis}

The experiments were carried out in a monopolar batch reactor using $1000 \mathrm{~mL}$ Plexiglas vessel that was fitted with a polycarbonate cell cover with slots to introduce the electrodes, $\mathrm{pH}$ sensor, a thermometer and the electrolytes. Titanium (Alfa Aesar, UK) of surface area $\left(0.02 \mathrm{~m}^{2}\right.$ ) acted as the anode. The cathode was galvanized iron (commercial grade, India) sheets of the same size as the anode is placed at an inter-electrode distance of $3 \mathrm{~cm}$. The temperature of the electrolyte was controlled to the desired value with a variation of $\pm 2 \mathrm{~K}$ by adjusting the rate of flow of thermostatically controlled water through an external glass-cooling spiral. A regulated direct current (DC) was supplied from a rectifier (10 A, 0-25 V; Aplab model).

The required concentration of manganese was prepared using Milli $Q$ water. In all the experiments $3 \mathrm{~g} \mathrm{~L}^{-1}$ of sodium chloride was used for better conductivity. The solution volume of 900 $\mathrm{mL}$ was used for each experiment as the electrolyte. The $\mathrm{pH}$ of the electrolyte was adjusted and measured initially and during the electrolysis by a $\mathrm{pH}$ meter (DKK-TOC, Japan). The $\mathrm{pH}$ was adjusted using either $0.1 \mathrm{M} \mathrm{NaOH}$ or $0.1 \mathrm{M} \mathrm{HCl}$ as necessary. After adjusting the initial solution $\mathrm{pH}$ to the desired value ( 3 to 9 ), the current density was set. The solution was stirred at $250 \mathrm{rpm}$ to ensure good mixing and transport of reactants. Temperature studies were carried at varying temperature (323-343 K) to determine the type of reaction.

\section{Analytical procedures}

The concentration of manganese was determined using UV-visible Spectrophotometer with manganese kits (MERCK, Pharo 300, Germany). The SEM image of titanium dioxide was analyzed with a Scanning Electron Microscope (SEM) made by Hitachi (model s-3000h). The constituents of the titanium dioxide were analyzed by X-Ray Fluorescence (XRF) made by Horiba (model XGT2700). The Fourier transform infrared spectrum of titanium dioxide was obtained using Nexus 670 FTIR spectrometer (Thermo Electron Corporation, USA) and X-ray diffraction (XRD) patterns of titanium dioxide was analyzed using an X'per PRO X-ray diffractometer (PANalytical, USA). TGA of titanium dioxide was carried out in the Thermal Analyzer (TA Instruments; Model SDT Q600). The concentration of carbonate, silicate, and phosphate were determined using UV-Visible spectrophotometer with respective standard ion kits supplied by MERCK (MERCK, Pharo 300). 


\section{Results and Discussion}

\section{Effect of current density on the removal efficiency}

The current density is one of the prominent factors which strongly influence the performance of electrodissolution process. The current density not only determines the coagulant dosage and bubble production rate but also the size and growth of the flocks, which can influence the treatment efficiency. Therefore, the effect of current density on the removal of manganese was investigated. Applying a constant current to the titanium effectively dissolved $\mathrm{Ti}$ according to $\mathrm{Ti} \rightarrow \mathrm{Ti}^{2+} \rightarrow \mathrm{TiO}^{2+}$. $\mathrm{TiO}^{2+}$ combined easily with $\mathrm{OH}^{-}$to form $\mathrm{TiO}_{2} \cdot \mathrm{H}_{2} \mathrm{O}$ or $\mathrm{Ti}(\mathrm{OH})_{4} \cdot \mathrm{Ti}(\mathrm{OH})_{4}$ is unstable substance, which changes gradually into $\mathrm{TiO}_{2} \cdot \mathrm{H}_{2} \mathrm{O}$ by dehydration. The reaction equations were,

$$
\mathrm{TiO}^{2+}+6 \mathrm{OH}^{-}+2 \mathrm{e}^{-} \rightarrow \mathrm{Ti}(\mathrm{OH})_{4}+\mathrm{H}_{2}+3 \mathrm{O}^{2-}
$$

and

$$
\mathrm{TiO}^{2+}+2 \mathrm{OH}^{-} \rightarrow \mathrm{TiO}_{2} \cdot \mathrm{H}_{2} \mathrm{O}
$$

and at the cathode the following reaction is taking place,

$$
2 \mathrm{H}_{2} \mathrm{O}+2 \mathrm{e}^{-} \rightarrow \mathrm{H}_{2}(\mathrm{~g})+2 \mathrm{OH}^{-}
$$

The amount of manganese removal depends upon the quantity of adsorbent (hydrous titanium dioxide) generated, which is related to the time and current density [27]. The amount of adsorbent was determined from Faraday's law. With the increase in current density the amount of hydrous titanium dioxide generation also increases. To investigate the effect of current density on the manganese removal, a series of experiments were carried out by solutions containing a constant pollutants loading of $2 \mathrm{mg} \mathrm{L}^{-1}$, at a pH 7.0, with current density being varied from 0.02 to $0.1 \mathrm{~A} \mathrm{dm}^{-2}$. The removal efficiencies are 60.25, 82.54, 90.10, 97.55 and $97.90 \%$ for $0.02,0.04,0.06,0.08$ and $0.1 \mathrm{~A} \mathrm{dm}^{-2}$ respectively. From the results, it was found that very small raise in removal efficiency was observed for current densities 0.08 and $0.1 \mathrm{~A} \mathrm{dm}^{-2}$. Hence, the further experiments were carried out at $0.08 \mathrm{~A} \mathrm{dm}^{-2}$.

\section{Effect of $\mathrm{pH}$ on the removal efficiency}

It is believed that the initial $\mathrm{pH}$ is an important operating factor influencing the performance of electrodissolution process. To explain this effect, a series of experiments were carried out using $2 \mathrm{mg} \mathrm{L}^{-1}$ of manganese containing solutions, by adjusting the initial pH in the interval from 3 to 9 .

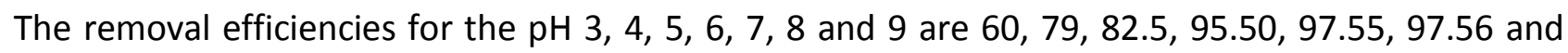
$97.65 \%$ respectively. It is well know that the titanium dioxide adsorption is $\mathrm{pH}$ dependent. At acidic $\mathrm{pH}$ it is positively charged while at alkaline $\mathrm{pH}$ it negatively charged. Mostly point of zero charge for titanium dioxide is approximately pH 6 to $8[28,29]$. The results agreed well with earlier results from the literature. Further experiments were carried out at $\mathrm{pH} 7$.

\section{Effect of electrolyte concentration}

In order to evaluate the effect of initial concentration of manganese, experiments were conducted with varying initial concentration from $0.25-2.0 \mathrm{mg} \mathrm{L}^{-1}$. Figure 1 shows that the uptake of manganese $\left(\mathrm{mg} \mathrm{g}^{-1}\right)$ increased with increase in manganese concentration and remained nearly constant after equilibrium time. The equilibrium time was found to be $180 \mathrm{~min}$ for all concentration studied. The amount of manganese adsorbed $\left(q_{\mathrm{e}}\right)$ increased from 0.248 to $1.982 \mathrm{mg}$ $\mathrm{g}^{-1}$ as the concentration increased from $0.25-2.0 \mathrm{mg} \mathrm{L}^{-1}$. From the Figure 1 it is found that the plots 
are single, smooth and continuous curves leading to saturation, suggesting the possible monolayer coverage to manganese on the surface of the adsorbent.

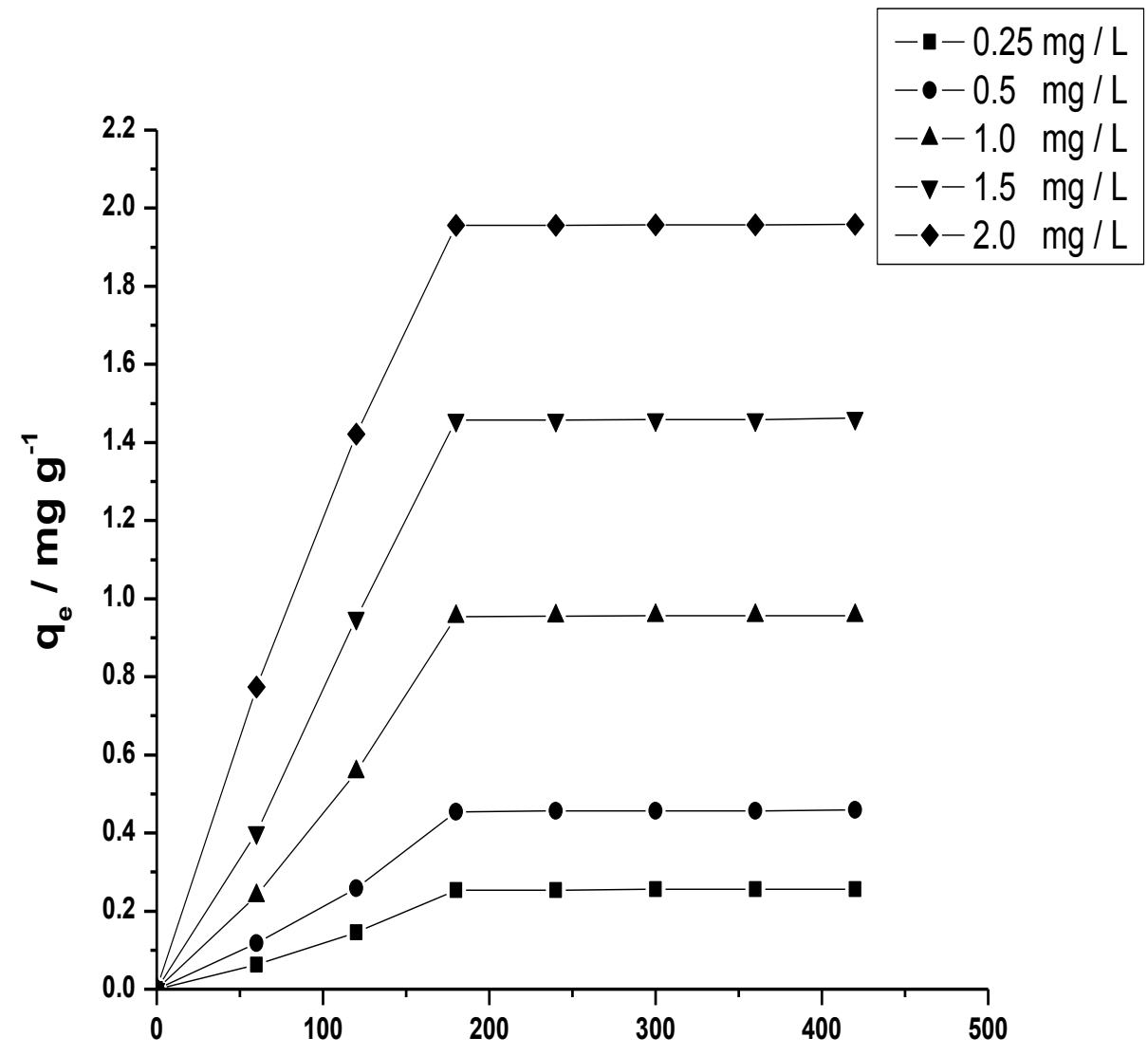

Time, $\min$

Figure 1. Effect of time and initial concentration of manganese for the adsorption on hydrous titanium dioxide, $\mathrm{pH} \mathrm{7.0,T}=303 \mathrm{~K}$.

\section{Effect of competing ions}

\section{Carbonate}

Effect of carbonate on manganese removal was evaluated by increasing the carbonate concentration from 0 to $250 \mathrm{mg} \mathrm{L}^{-1}$ in the electrolyte. The removal efficiencies are $97.55,95.3$, 72.8, 50.7, 38, and $19 \%$ for the carbonate concentration of $0,2,5,65,150$ and $250 \mathrm{mg} \mathrm{L}^{-1}$, respectively. From the results it is found that the removal efficiency of the manganese is not affected by the presence of carbonate below $2 \mathrm{mg} \mathrm{L}^{-1}$. Significant reduction in removal efficiency was observed above $5 \mathrm{mg} \mathrm{L}^{-1}$ of carbonate concentration is due to the passivation of anode resulting, the hindering of the dissolution process of anode [30].

\section{Phosphate}

The concentration of phosphate ion was increased from 0 to $50 \mathrm{mg} \mathrm{L}^{-1}$, the contaminant range of phosphate in the ground water. The removal efficiency for manganese was 97.55, 91.3, 60.7, 35.5 and $29.2 \%$ for $0,2,5,25$ and $50 \mathrm{mg} \mathrm{L}^{-1}$ of phosphate ion, respectively. There was no change in removal efficiency of manganese below $2 \mathrm{mg} \mathrm{L}^{-1}$ of phosphate in the water. At higher concentrations (at and above $5 \mathrm{mg} / \mathrm{L}$ ) of phosphate, the removal efficiency decreased drastically. This was due to the preferential adsorption of phosphate over manganese as the concentration of phosphate increased. 
Arsenic

The concentration of arsenic was gradually increased from 0 to $5 \mathrm{mg} \mathrm{L}^{-1}$. From the results it was found that the efficiency decrease for manganese was $97.55,90.7,78.5,68.6$ and $44.6 \%$ by increasing the concentration of arsenate from $0,0.2,0.5,2.5$ and $5.0 \mathrm{mg} \mathrm{L}^{-1}$, respectively. This was due to the preferential adsorption of arsenic over manganese as the concentration of arsenate increases. So, when arsenic ions are present in the water to be treated arsenic ions compete greatly with manganese ions for the binding sites.

\section{Silicate}

From the results it is found that no significant change in manganese removal was observed, when the silicate concentration was increased from 0 to $2 \mathrm{mg} \mathrm{L}^{-1}$. The respective efficiencies for $0,2,5,10$ and $15 \mathrm{mg} \mathrm{L}^{-1}$ of silicate are 97.55, 80.2, 72.4, 51.6 and $43.8 \%$. In addition to preferential adsorption, silicate can interact with titanium dioxide to form soluble and highly dispersed colloids that are not removed by normal filtration [30].

\section{Adsorption kinetic modeling}

The kinetic studies predict the progress of adsorption; however, the determination of the adsorption mechanism is also important for design purposes. In this research investigation, firstand second order kinetic models were tested at different concentration ( 0.25 to $\left.2.0 \mathrm{mg} \mathrm{L}^{-1}\right)$ at a current density of $0.08 \mathrm{~A} \mathrm{dm}^{-2}$.

\section{First order kinetic model}

The first order kinetic model is generally expressed as follows [31],

$$
\mathrm{d} q_{\mathrm{t}} / \mathrm{d} t=k_{1}\left(q_{\mathrm{e}}-q_{\mathrm{t}}\right)
$$

where $q_{\mathrm{e}} / \mathrm{mg} \mathrm{g}^{-1}$ and $q_{\mathrm{t}} / \mathrm{mg} \mathrm{g}^{-1}$ are the adsorption capacities at equilibrium and at time $t / \mathrm{min}$ respectively, and $k_{1} / \mathrm{min}^{-1}$ is a rate constant of first order adsorption. The integrated form of the above equation with the boundary conditions $t=0$ to $t=\mathrm{t}$ and $q_{\mathrm{t}}=0$ to $q_{\mathrm{t}}=q_{\mathrm{t}}$ is rearranged to obtain the following time dependence function,

$$
\log \left(q_{\mathrm{e}}-q_{\mathrm{t}}\right)=\log q_{\mathrm{e}}-k_{1} t / 2.303
$$

The experimental data were analyzed initially with first order model. The plot of $\log \left(q_{\mathrm{e}}-q_{\mathrm{t}}\right) v s . t$ should give the linear relationship from which $k_{1}$ and $q_{\mathrm{e}}$ can be determined by the slope and intercept, respectively Eq. (5). The computed results are presented in Table 1 . The results show that the theoretical $q_{\mathrm{e}}$ (cal) value doesn't agree to the experimental $q_{\mathrm{e}}(\exp )$ values at all concentrations studied with poor correlation coefficient. This result indicated that the adsorption system do not follow a first-order reaction. So, further the experimental data were fitted with second order model.

\section{Second order kinetic model}

The second order kinetic model is expressed as [32],

$$
\mathrm{d} q_{\mathrm{t}} / \mathrm{d} t=k_{2}\left(q_{\mathrm{e}}-q_{\mathrm{t}}\right)^{2}
$$

The integrated form of Eq. (6) with the boundary condition $t=0$ to $t=t$ and $q_{\mathrm{t}}=0$ to $q_{\mathrm{t}}=q_{\mathrm{t}}$ is,

$$
1 /\left(q_{\mathrm{e}}-q_{\mathrm{t}}\right)=1 / q_{\mathrm{e}}+k_{2} t
$$

Eq. (7) can be rearranged and linearized as, 


$$
t / q_{\mathrm{t}}=1 / k_{2} q_{\mathrm{e}}^{2}+t / q_{\mathrm{e}}
$$

where, $q_{\mathrm{e}} / \mathrm{mg} \mathrm{g}^{-1}$ and $q_{\mathrm{t}} / \mathrm{mg} \mathrm{g}^{-1}$ are the amount of manganese adsorbed on hydrous titanium dioxide at equilibrium and at time $t / \mathrm{min}$, respectively, and $k_{2}$ is the rate constant for the second order kinetic model.

Table 1 Comparison between the experimental and calculated $q_{e}$ values at different concentrations in first order and second order adsorption kinetics at a current density of $0.08 \mathrm{~A} \mathrm{dm}^{-2}$.

\begin{tabular}{cccccccc}
\hline & & \multicolumn{3}{c}{ Pseudo first order adsorption } & \multicolumn{3}{c}{ Pseudo Second order adsorption } \\
\cline { 3 - 7 }$C / \mathrm{mg} \mathrm{L}^{-1}$ & $\begin{array}{c}q_{\mathrm{e}} / \mathrm{mg} \mathrm{g}^{-1} \\
\text { (exp) }\end{array}$ & $\begin{array}{c}q_{\mathrm{e}} / \mathrm{mg} \mathrm{g}^{-1} \\
\text { (cal) }\end{array}$ & $k_{1} / \mathrm{min}^{-1}$ & $R^{2}$ & $\begin{array}{c}q_{\mathrm{e}} / \mathrm{mg} \mathrm{g}^{-1} \\
\text { (cal) }\end{array}$ & $k_{2} /\left(\mathrm{g} \mathrm{mg}^{-1}\right) \mathrm{min}^{-1}$ & $R^{2}$ \\
\hline 0.25 & 0.248 & 35.78 & 0.0244 & 0.0069 & 0.248 & 1.6715 & 0.992 \\
0.50 & 0.463 & 22.84 & 0.0212 & 0.0204 & 0.461 & 0.1013 & 0.991 \\
1.0 & 0.951 & 1.543 & 0.0168 & 0.6154 & 0.950 & 0.1071 & 0.995 \\
1.5 & 1.470 & 1.337 & 0.0124 & 0.3462 & 1.470 & 0.0874 & 0.986 \\
2.0 & 1.982 & 5.780 & 0.0178 & 0.3425 & 1.980 & 0.0343 & 0.987 \\
\hline
\end{tabular}

The kinetic data were fitted to the second order model Eq. (8). The equilibrium adsorption capacity, $q_{\mathrm{e}}$ (cal) and $k_{2}$ were determined from the slope and intercept of plot of $t / q_{\mathrm{t}}$ versus $t$ and are compiled in Table 1. Figure 2 shows the plot of $t / q_{\mathrm{t}}$ versus $t$ for manganese adsorption and the plots were found to be linear. The theoretical $q_{\mathrm{e}}$ (cal) value also agreed very well with the experimental $q_{\mathrm{e}}$ value, indicating the pseudo second-order kinetics. In addition, the correlation coefficient for the second-order kinetic model was 0.99 , which suggest the applicability of this kinetic equation and the second-order nature of the sorption process of manganese on hydrous titanium dioxide.

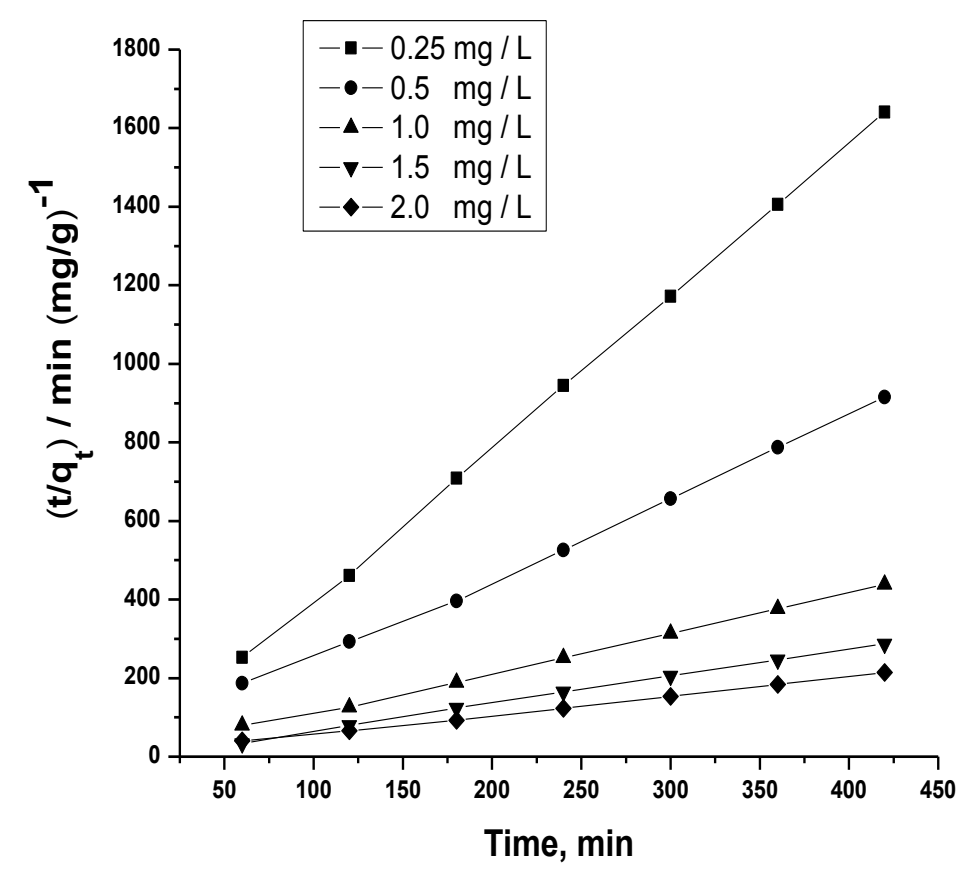

Figure 2. Second-order kinetic model plots for adsorption of manganese at different concentrations, $\mathrm{pH}$ of the electrolyte: 7.0 , temperature: $303 \mathrm{~K}$, current density: $0.08 \mathrm{~A} \mathrm{dm}^{-2}$

The computed results obtained from first order and second order models were depicted in Table 1. From the tables, it was found that the correlation coefficient values are in the order of 
second order $>$ first order. This indicates that the adsorption follows the second order model. Further, the calculated $q_{\mathrm{e}}$ values well agree with the experimental $q_{\mathrm{e}}$ values for second order kinetics model. These results indicate that the second-order kinetic model can be applied suitably to predict the manganese adsorption process onto hydrous titanium dioxide.

\section{Isotherm modeling}

In order to explain the mechanism of the adsorption process, it is important to establish the most appropriate correlation for the equilibrium curves. In this study, three adsorption isotherms viz., Freundlich, Langmuir and Redlich isotherm models were applied to establish the relationship between the amounts of manganese adsorbed onto the hydrous titanium hydroxide and its equilibrium concentration in the electrolyte containing contaminant ions.

\section{Freundlich Isotherm}

The Freundlich adsorption isotherm typically fits the experimental data over a wide range of concentrations. This empirical model includes considerations of surface heterogeneity and exponential distribution of the active sites and their energies. The isotherm is adopted to describe reversible adsorption and is not restricted to monolayer formation. The linearised in logarithmic form and the Freundlich constants can be expressed as [33],

$$
\log q_{\mathrm{e}}=\log k_{\mathrm{f}}+\mathrm{n} \log C_{\mathrm{e}}
$$

where, $k_{\mathrm{f}}$ is the Freundlich constant related to adsorption capacity, $n$ is the energy or intensity of adsorption, $C_{\mathrm{e}}$ is the equilibrium concentration of manganese $\left(\mathrm{mg} \mathrm{L}^{-1}\right)$.

In testing the isotherm, the manganese concentration used was 0.25 to $2.0 \mathrm{mg} \mathrm{L}^{-1}$, current density of $0.08 \mathrm{~A} \mathrm{dm}^{-2}$ and at an initial $\mathrm{pH}$ 7. The adsorption data is plotted as log $\mathrm{q}_{\mathrm{e}}$ versus $\log C_{\mathrm{e}}$ by equation (9) should result in a straight line with slope $n$ and intercept $k_{\mathrm{f}}$. The intercept and the slope are indicators of adsorption capacity and adsorption intensity, respectively. The value of $n$ falling in the range of 1-10 indicates favorable sorption. Freundlich constant $\left(k_{\mathrm{f}}\right)$ and $\mathrm{n}$ values were listed in Table 2. From the analysis of the results it is found that the Freundlich plots fit only satisfactorily with the experimental data obtained in the present study which is shown in the Figure. 3 (a).

Table 2 Constant parameters and correlation coefficient for different adsorption isotherm models for manganese adsorption at $0.25-2.0 \mathrm{mg} \mathrm{L}^{-1}$ at a current density of $0.08 \mathrm{~A} \mathrm{dm}^{-2}$

\begin{tabular}{lllllll}
\hline \multirow{2}{*}{ Isotherm } & \multicolumn{1}{c}{ Parameters } & 0.25 & 0.5 & 1.5 & 1.5 & 2.0 \\
\hline \multirow{2}{*}{ Langmuir } & $q_{\mathrm{m}} / \mathrm{mg} \mathrm{g}^{-1}$ & 0.2383 & 0.4597 & 0.9564 & 1.4616 & 1.9491 \\
\cline { 2 - 6 } & $b / \mathrm{L} \mathrm{mg}^{-1}$ & 0.1113 & 0.1102 & 0.1099 & 0.1014 & 0.0948 \\
\cline { 2 - 6 } & $R^{2}$ & 0.9943 & 0.9987 & 0.9954 & 0.9962 & 0.9991 \\
\cline { 2 - 6 } & $R_{\mathrm{L}}$ & 0.9729 & 0.9479 & 0.8998 & 0.8569 & 0.8179 \\
\hline \multirow{3}{*}{ Freundlich } & $k_{\mathrm{f}} / \mathrm{mg} \mathrm{g}^{-1}$ & 0.5803 & 0.5512 & 0.5174 & 0.4897 & 0.4613 \\
\cline { 2 - 6 } & $\mathrm{n} / \mathrm{L} \mathrm{mg-1)}^{2}$ & 2.1786 & 2.0257 & 1.9457 & 1.8798 & 1.7259 \\
\cline { 2 - 6 } Redlich & $R^{2}$ & 0.9812 & 0.9789 & 0.9881 & 0.9836 & 0.9820 \\
\cline { 2 - 6 } Peterson & $K_{\mathrm{F}} / \mathrm{Lg}^{-1}$ & 0.9978 & 0.9981 & 0.9968 & 0.9990 & 0.9891 \\
\hline & $\beta$ & 0.9764 & 0.9854 & 0.9817 & 0.9897 & 0.9789 \\
\hline
\end{tabular}



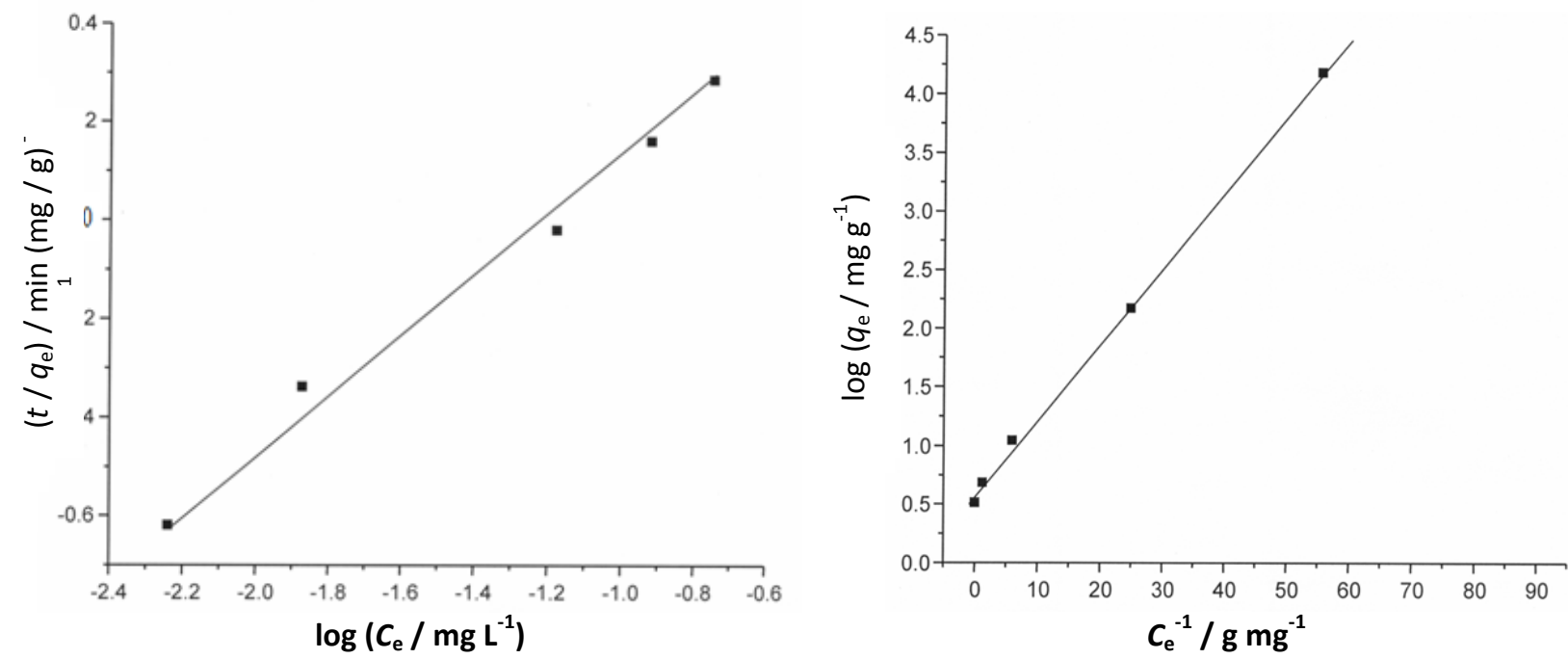

Figure 3. (a) Frendlich plot ( $\left.\log q_{e} v s \log C_{e}\right)$ for adsorption of manganese, $p H$ of the electrolyte: 7.0, current density: $0.08 \mathrm{~A} \mathrm{dm}^{-2}$, concentration: $2.0 \mathrm{mg} \mathrm{L}^{-1}$, (b) Langmuir plot (1/qe vs. 1/Ce) for adsorption of manganese, $\mathrm{pH}$ of the electrolyte: 7.0 , current density: $0.08 \mathrm{~A} \mathrm{dm}^{-2}$, concentration: $2.0 \mathrm{mg} \mathrm{L}^{-1}$

\section{Langmuir Isotherm}

This model assumes a monolayer deposition on a surface with a finite number of identical sites. It is well known that the Langmuir equation is valid for a homogeneous surface. The linearized form of Langmuir adsorption isotherm model is [34],

$$
C_{\mathrm{e}} / q_{\mathrm{e}}=1 / q_{\mathrm{m}} b+C_{\mathrm{e}} / q_{\mathrm{m}}
$$

where, $q_{\mathrm{e}}$ is amount adsorbed at equilibrium, $C_{\mathrm{e}}$ is the equilibrium concentration, $q_{\mathrm{m}}$ is the Langmuir constant representing maximum monolayer adsorption capacity and $b$ is the Langmuir constant related to energy of adsorption. The essential characteristics of the Langmuir isotherm can be expressed as the dimensionless constant $R_{\mathrm{L}}$.

$$
R_{\mathrm{L}}=1 /\left(1+b C_{\mathrm{o}}\right)
$$

where $R_{\mathrm{L}}$ is the equilibrium constant it indicates the type of adsorption, $b$, is the Langmuir constant. $C_{\mathrm{o}}$ is various concentration of manganese solution. The $R_{\mathrm{L}}$ values between 0 and 1 indicate the favorable adsorption.

Langmuir isotherm was tested from Eq. (10). The plots of $1 / q_{\mathrm{e}}$ as a function of $1 / C_{\mathrm{e}}$ for the adsorption of manganese on hydrous titanium dioxide are shown in Figure 3 (b). The plots were found linear with good correlation coefficients (>0.99) indicating the applicability of Langmuir model in the present study. The values of monolayer capacity $\left(q_{m}\right)$ and Langmuir constant $(b)$ is presented in Table 2. The values of $q_{\mathrm{m}}$ calculated by the Langmuir isotherm were all close to experimental values at given experimental conditions. These facts suggest that manganese is adsorbed in the form of monolayer coverage on the surface of the adsorbent. The dimensionless constant $R_{\mathrm{L}}$ was calculated from Eq.(11). The $R_{\mathrm{L}}$ values were found to be between 0 and 1 for all the concentration of manganese studied. The correlation co-efficient values of Langmuir and Freundlich isotherm models are presented in Table 2.

\section{Redlich Peterson isotherm}

It is a three parameter hybrid isotherm. It is having features of both the Langmuir and Frendlich isotherms. This model has linear dependence in the numerator component and exponential component in denominator of non-linear form $[35,36]$. 


$$
q_{\mathrm{e}}=\frac{K_{\mathrm{F}} C_{\mathrm{e}}}{1+a_{\mathrm{R}} C_{\mathrm{e}}^{\beta}}
$$

where $q_{e} / \mathrm{mmol} \mathrm{g}^{-1}$ is the solid-phase sorbate concentration at equilibrium, $C_{e} / \mathrm{mmol} \mathrm{L}^{-1}$ is the concentration of adsorbate in equilibrium with liquid phase, $K_{F} / \mathrm{L} \mathrm{g}^{-1}$ and $a_{R} / \mathrm{L} \mathrm{mmol}^{-(1-1 / \beta)}$ are the Redlich-Peterson isotherm constants, and $\beta$ is the exponent, which lies between 1 and 0 . If the $\beta$ tends to 0 then the adsorption follows the Frendlich isotherm and if the $\beta$ value tends to one it fits with the Langmuir isotherm. In order to verify our investigation regarding the monolayer or multilayer adsorption, the linear form of Redlich-Peterson is used. It is little bit complicated compared to the other isotherms. The strategy to find these parameters is based in the maximization of correlation coefficients $\left(R^{2}\right)$ from the linear fit to the data. In this way the $K_{F}$ values are modified until obtain the best fit of the data. The linear form of the equation for this model is

$$
\ln \left(K_{\mathrm{F}}\left(C_{\mathrm{e}} / q_{\mathrm{e}}-1\right)=\ln a_{\mathrm{R}}+\beta \ln C_{\mathrm{e}}\right.
$$

Plotting of $\ln \left(K_{\mathrm{F}}\left(C_{\mathrm{e}} / q_{\mathrm{e}}-1\right)\right.$ vs. In $C_{\mathrm{e}}$ by the Eq. (13) gives the Redlich Peterson equation. This isotherm is a three parameters isotherm in which $K_{\mathrm{F}}$ values are indirectly obtained by plotting the graph with maximum correlation coefficient by justifying the values of $K_{\mathrm{F}}$. By that $K_{\mathrm{F}}, \beta$ and $a_{\mathrm{R}}$ are in the Table 2 for all concentrations. Here the $\beta$ values are above the 0.95 . So the adsorption favors Langmuir isotherm rather than Frendlich isotherm.

\section{Adsorption thermodynamics}

To understand the effect of temperature on adsorption process, thermodynamic parameters should be determined at various temperatures. The energy of activation for adsorption of manganese can be determined by the second order rate constant is expressed in Arrhenius form [37],

$$
\ln k_{2}=\ln k_{\mathrm{o}}-E / R T
$$

where $k_{\mathrm{o}}$ is the constant of the equation $\left.\left(\mathrm{g} \mathrm{mg}^{-1}\right) \mathrm{min}^{-1}\right), E$ is the energy of activation $\left(\mathrm{J} \mathrm{mol}^{-1}\right), R$ is the gas constant $\left(8.314 \mathrm{~J} \mathrm{~mol}^{-1} \mathrm{~K}^{-1}\right)$ and $T$ is the temperature $(\mathrm{K})$. Figure $4(\mathrm{a})$ shows that the rate constants vary with temperature according to Eq.(14) giving an activation energy of $21.01 \mathrm{~kJ} \mathrm{~mol}^{-1}$ for manganese from the slope of the fitted equation. The free energy change is obtained using the following relationship

$$
\Delta G=-R T \ln K_{\mathrm{c}}
$$

where $\Delta G$ is the free energy $\left(\mathrm{kJ} \mathrm{mol}^{-1}\right), K_{\mathrm{c}}$ is the equilibrium constant, $R$ is the universal gas constant and $T$ is the temperature in $\mathrm{K}$. The values of $K_{\mathrm{c}}$ and $\Delta G$ are presented in Table 3. The negative value of $\Delta G$ indicates the spontaneous nature of adsorption. Other thermodynamic parameters such as entropy change $(\Delta S)$ and enthalpy change $(\Delta H)$ were determined using the van't Hoff equation:

$$
\ln K_{\mathrm{c}}=\frac{\Delta S}{R}-\frac{\Delta H}{R T}
$$

The enthalpy change $\left(\Delta H=-60.57 \mathrm{~J} \mathrm{~mol}^{-1}\right)$ and entropy change $\left(\Delta S=-0.047 \mathrm{~J} \mathrm{~mol}^{-1} \mathrm{~K}^{-1}\right)$ were obtained from the slopes and intercepts of the van't Hoff linear plots of In $K_{\mathrm{c}}$ versus $1 / T$ (Figure. 4(b)) Eq.(16). Negative value of enthalpy change $(\Delta H)$ indicates that the adsorption process is exothermic in nature, and the negative value of change in internal energy $(\Delta G)$ show the spontaneous adsorption of manganese on the adsorbent. Negative values of entropy change show 
the increased randomness of the solution interface which gains heat from the surroundings during adsorption of manganese on the adsorbent [38] (Table 3). Negative enthalpy and negative entropy shows that the adsorption is more favorable at low temperature. This is due to the decrement of pore size as temperature increases.
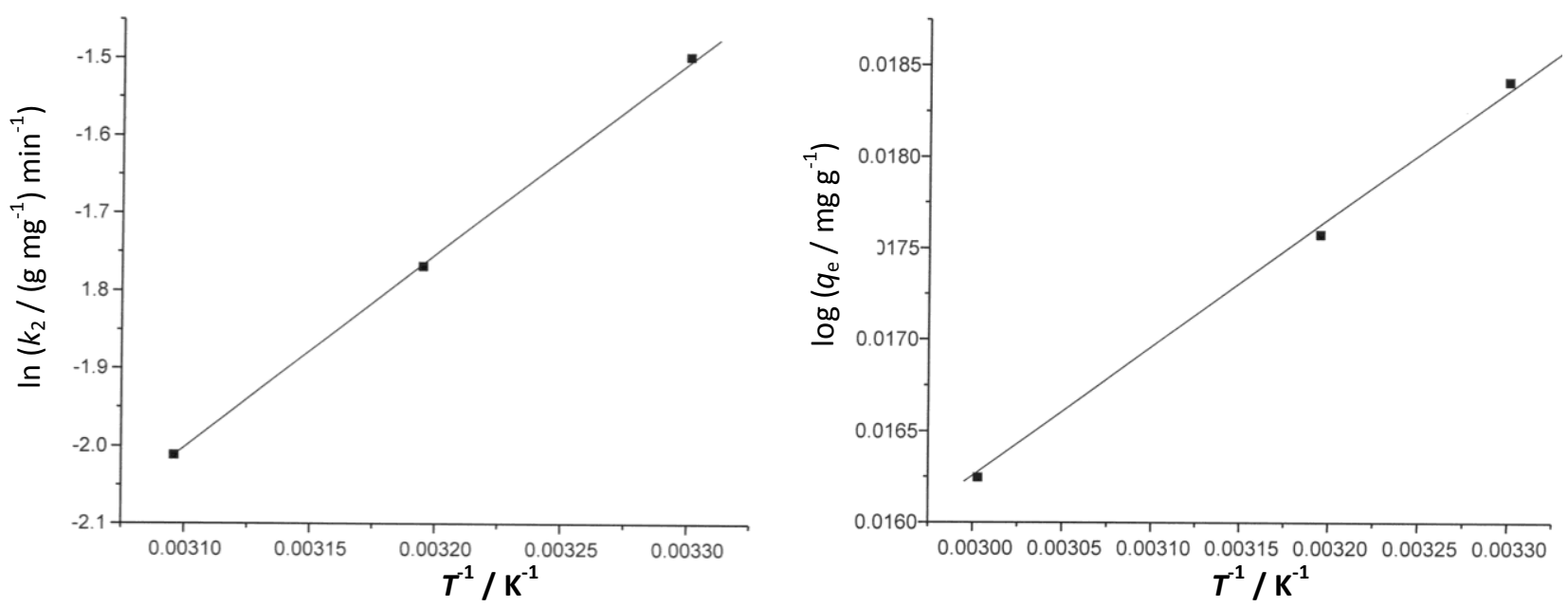

Figure 4. (a) Plot of log $\mathrm{k}_{2}$ vs. $\mathrm{T}^{-1}$; (b) Plot of $\ln \mathrm{K}_{c}$ vs. $\mathrm{T}^{-1}: p H 7.0 ; \mathrm{j}=0.08 \mathrm{Adm}^{-2}, \mathrm{C}=2 \mathrm{mg} \mathrm{L}^{-1}$

The enthalpy change $\left(\Delta H=-60.57 \mathrm{~J} \mathrm{~mol}^{-1}\right)$ and entropy change $\left(\Delta S=-0.047 \mathrm{~J} \mathrm{~mol}^{-1} \mathrm{~K}^{-1}\right)$ were obtained from the slopes and intercepts of the van't Hoff linear plots of In $K_{\mathrm{c}}$ versus $1 / T$ (Figure. 4(b)) Eq.(16). Negative value of enthalpy change $(\Delta H)$ indicates that the adsorption process is exothermic in nature, and the negative value of change in internal energy $(\Delta G)$ show the spontaneous adsorption of manganese on the adsorbent. Negative values of entropy change show the increased randomness of the solution interface which gains heat from the surroundings during adsorption of manganese on the adsorbent [38] (Table 3). Negative enthalpy and negative entropy shows that the adsorption is more favorable at low temperature. This is due to the decrement of pore size as temperature increases.

Table 3 Thermodynamics parameters for adsorption of manganese.

\begin{tabular}{ccccc}
\hline Temperature, $\mathrm{K}$ & $K_{\mathrm{c}}$ & $\Delta G^{\circ} / \mathrm{kJ} \mathrm{mol}^{-1}$ & $\Delta H^{\circ} / \mathrm{Jmol}^{-1}$ & $\Delta S^{\circ} / \mathrm{J} \mathrm{mol}^{-1} \mathrm{~K}^{-1}$ \\
\hline 323 & 1.0433 & -0.0464 & & \\
333 & 1.0406 & -0.0450 & -60.57 & -0.0470 \\
343 & 1.0382 & -0.0436 & & \\
\hline
\end{tabular}

Table 4. Comparison between the experimental and calculated $\mathrm{q}_{e}$ values at different temperatures in first and second order adsorption kinetics of manganese: $\mathrm{C}=2.0 \mathrm{mg} \mathrm{L}^{-1}, \mathrm{pH} 7.0, \mathrm{j}=0.08 \mathrm{Adm}^{-2}$

\begin{tabular}{cccccccc}
\hline & & \multicolumn{3}{c}{ First order adsorption } & \multicolumn{3}{c}{ Second order adsorption } \\
\cline { 3 - 8 }$T / \mathrm{K}$ & $\begin{array}{c}q_{\mathrm{e}} / \mathrm{mg} \mathrm{g}^{-1} \\
\text { (exp) }\end{array}$ & $\begin{array}{c}q_{\mathrm{e}} / \mathrm{mg} \mathrm{g}^{-1} \\
\text { (cal) }\end{array}$ & $\mathrm{k}_{1} / \mathrm{min}^{-1}$ & $R^{2}$ & $\begin{array}{c}q_{\mathrm{e}} / \mathrm{mg} \mathrm{g}^{-1} \\
\text { (cal) }\end{array}$ & $\left.k_{2} / \mathrm{g} \mathrm{mg}^{-1}\right) \mathrm{min}^{-1}$ & $R^{2}$ \\
\hline 323 & 2.048 & 1.112 & -0.0061 & 0.5430 & 2.01 & 0.0320 & 0.990 \\
333 & 2.160 & 0.987 & -0.0068 & 0.4569 & 2.13 & 0.0095 & 0.986 \\
343 & 2.165 & 0.874 & -0.0071 & 0.4037 & 2.14 & 0.0097 & 0.991 \\
\hline
\end{tabular}

Using Lagergren rate equation, pseudo second order rate constants and correlation co-efficient were calculated for different temperatures $(323-343 \mathrm{~K})$. The calculated $q_{\mathrm{e}}$ values obtained from the second order kinetics agrees with the experimental $q_{\mathrm{e}}$ values better than the first order 
kinetics model, indicating adsorption following second order kinetics. Table 4 depicts the computed results obtained from pseudo first and pseudo second order kinetic models.

\section{Characterization of hydrous titanium dioxide}

\section{XRF studies}

The contents of titanium dioxide were analyzed by XRF. The titanium dioxide sample was dried in a drying chamber at $100{ }^{\circ} \mathrm{C}$ were ground in the agate mortar. As shown in Table $5,95.2 \%$ of the sample, by weight, was titanium dioxide. Sodium chloride was came from the electrolyte, and calcium and barium elements came from the impurity in the titanium electrode.

\section{XRD studies}

The crystal structure of hydrous titanium dioxide nanoparticles was analyzed by X-ray powder diffractometer operating with $\mathrm{CuK} \alpha$ radiation source filtered with a graphite monochromator. Figure. 5(a) shows the X-ray diffraction pattern of hydrous titanium dioxide nanoparticles. From the figure it is found that, most diffraction peaks belong to the anatase phase (JCPDS Card Number 73-1764), and minor peaks from the brookite phase (JCPDS Card Number 76-1936) could also be observed. The crystallite size $D$ was determined from the broadening of corresponding strongest X-ray diffraction peaks by using Scherrer's formula [39]:

$$
D=\frac{0.9 \lambda}{\beta \cos \theta}
$$

where $D$ is the crystalline size, $\lambda$ is the average wavelength of the $X$-ray radiation $(\lambda=1.5418 \AA$ ),$\beta$ is the line-width at half-maximum peak position, and $\theta$ is the diffracting angle $\left(2 \theta=25.4^{\circ}\right)$. The average crystallite size of the hydrous titanium dioxide is $4.3-8.4 \mathrm{~nm}$.

\section{FT-IR spectrum}

The hydrous titanium dioxide was analyzed using FTIR and results are presented in Figure 5(b). The strong peak at $3381 \mathrm{~cm}^{-1}$ is attributed to the stretching vibrations of surface and interlayer water molecules and hydroxyl groups. This is related to the formation of hydrogen bonds of interlayer water with guest anions as well as with hydroxide groups of layers. At $1630.18 \mathrm{~cm}^{-1}$, there is a strong adsorption peak for hydroxyl bending vibration belonging to physically adsorbed $\mathrm{H}_{2} \mathrm{O}$. One small adsorption peak could also be identified at $1371.37 \mathrm{~cm}^{-1}$, which represents the coordinated hydroxyl groups. These observations demonstrate that these hydrous titanium dioxide nanoparticles have high adsorption capacities to $\mathrm{H}_{2} \mathrm{O}$ and hydroxyl groups exist on their surfaces [40].

\section{SEM and EDAX analysis}

Figure 5(c) shows the SEM images of hydrous titanium dioxide. The SEM images show different size, shape and dimension and these nanoparticles are aggregated into micro-sized particles. The volume median diameter value of these nanoparticles in distilled water was determined at approximately $9.8 \mathrm{~nm}$ by the dynamic light scattering technique, which is in accordance with the SEM observation. This type of aggregation of nanoparticles is beneficial to their removal from aqueous environment after the treatment process.

Energy-dispersive analysis of X-rays was used to analyze the elemental constituents of titanium dioxide generated during the electro dissolution process and the results are presented in Figure 5(d). The figure indicates that the titanium dioxide was composed mainly of $\mathrm{Ti}$ an $\mathrm{O}$, which affirms that the titanium dioxide was generated by anodic dissolution. 
a

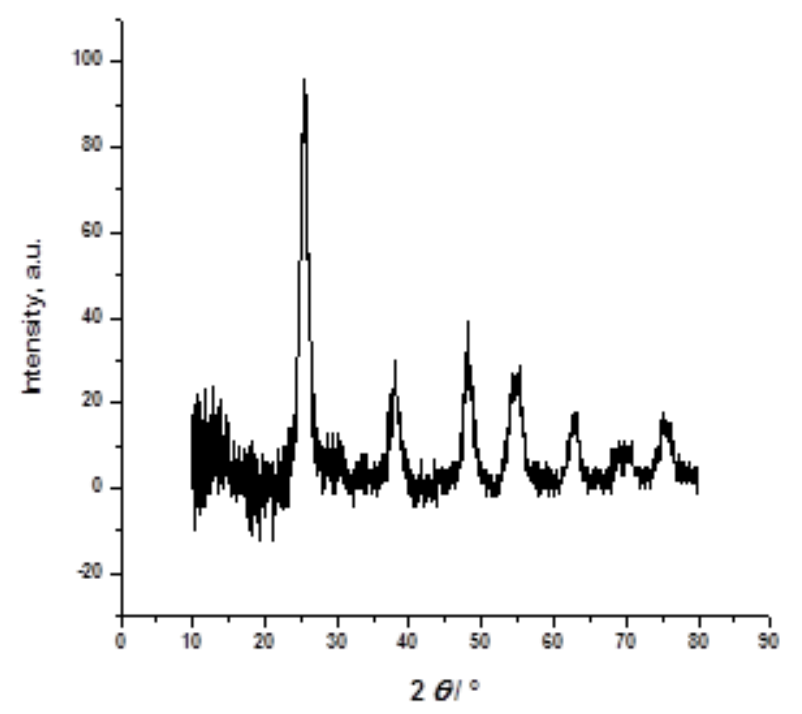

C

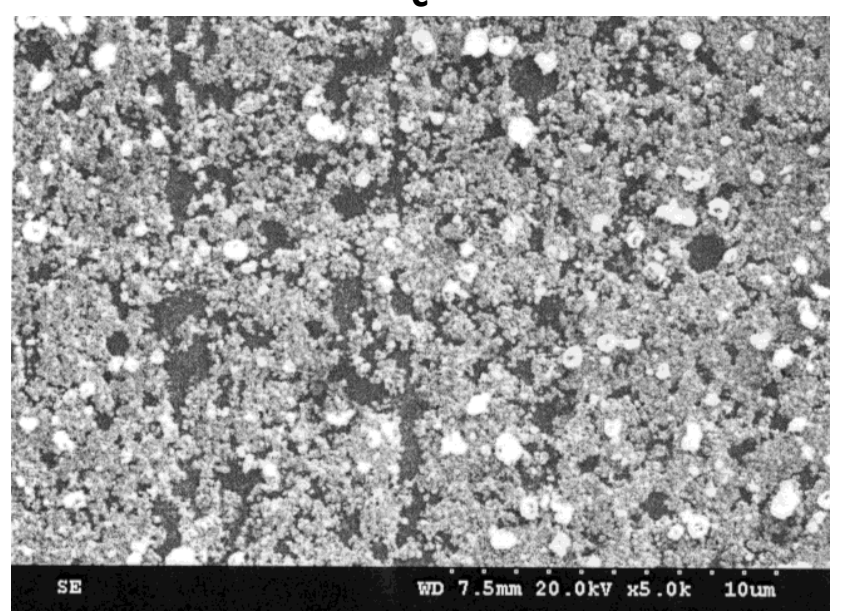

b

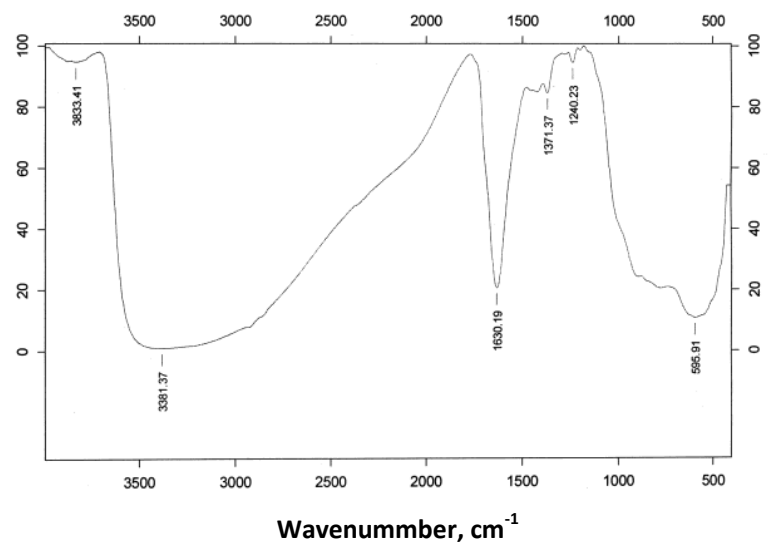

d

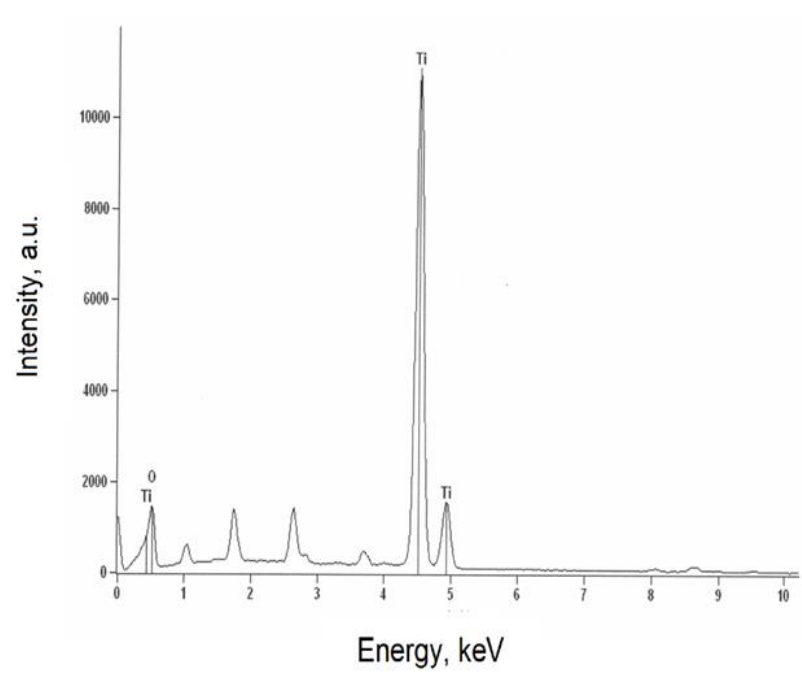

Figure 5. (a) X-ray diffraction pattern of hydrous $\mathrm{TiO}_{2}$, (b) FTIR pattern of hydrous $\mathrm{TiO}_{2}$, (c) SEM image of the hydrous $\mathrm{TiO}_{2}$, (d) EDAX image of the hydrous $\mathrm{TiO}_{2}$

TGA analysis

TGA analysis (figure not shown) of hydrous titanium dioxide was carried out. From the results we found that the weight loss of $13.0 \%$ where observed when the samples were heated from the $32-800^{\circ} \mathrm{C}$. The entire range will be divided into three stages viz., first, second and third stage. In the first stage $\left(32-122^{\circ} \mathrm{C}\right)$ weight loss $(6.9 \%)$ could be attributed to the elimination of physically absorbed water. In the second stage $\left(122\right.$ to $\left.438^{\circ} \mathrm{C}\right)$ weight loss $(6.0 \%)$ could be contributed to the loss of surface hydroxyl groups. In the third stage (438 to $800^{\circ} \mathrm{C}$ ) no exothermic peak was observed and the weight loss is around $0.1 \%$.

\section{Conclusions}

The maximum removal efficiency of $97.55 \%$ was achieved with titanium as sacrificial anode at a current density of $0.08 \mathrm{~A} \mathrm{dm}^{-2}, \mathrm{pH} 7.0$. The results indicate that the hydrous titanium dioxide, by electro-dissolution of sacrificial anodes, efficiently adsorbs the manganese from water. Hence this process can be used as an effective process for the removal of manganese contaminated water resources. The results indicate that, the second-order kinetic model accurately described the adsorption kinetics. The adsorption mechanism was found to be chemisorption and the rate- 
limiting step was mainly surface adsorption. The Langmuir isotherm showed a better fit than the Freundlich and Redlich isotherms, thus, indicating the applicability of monolayer coverage of manganese on hydrous titanium dioxide.

The thermodynamic parameters like $\Delta G, \Delta H$ and $\Delta S$ were determined. Their values indicated that the adsorption process was favorable, spontaneous, and exothermic in nature. As the temperature increased $\Delta G$ became less negative, indicating a stronger driving force, resulting in a greater adsorption capacity at higher temperatures. The negative value of $\Delta H$ confirmed that the process was exothermic. Negative values of entropy change show the increased randomness of the solution interface which gains heat from the surroundings during adsorption of manganese on the adsorbent. EDAX analysis confirmed that manganese was adsorbed on to the hydrous titanium dioxide.

Acknowledgments: The authors wish to express their gratitude to Dr. Vijayamohanan K. Pillai, Director, CSIR-Central Electrochemical Research Institute, Karaikudi to publish this article.

\section{References}

[1] Y. H. Chang, K. H. Hsieh, F. C. Chang, Journal of Applied Polymer Science 112 (2009) 24452454.

[2] K. Kannan, Fundamentals of Environmental Pollution, S Chand Co. Limited, New Delhi, 1995

[3] Y. C. Sharma Uma, S. N. Singh Paras, F. Gode, Chemical Engineering Journal 132 (2007) 319323.

[4] A. Takeda, Brain Research Reviews 41 (2003) 79-87.

[5] J. Donaldson, Neuro Toxicology 8 (1987) 451-462.

[6] S. M. Bamforth, D. A.C. Manning, I. Singleton, P. L. Younger, K. L. Johnson, Applied Geochemistry 21 (2006) 1274-1287

[7] R. W. Leggett, Science of the Total Environment 409 (2011) 4179-4186

[8] M. K. Doula, Water Research 40 (2006) 3167-3176.

[9] World Health Organization, Manganese in drinking water, Background document for development of WHO guidelines for drinking water quality report: 2011. (www.who.int/ Lwater sanitation health/dwq/chemicals/manganese.pdf), accessed November 2014

[10] S. R. Taffarel, J. Rubio, Minerals Engineering 22 (2009) 336-343

[11] M. K. Doula, Water Research 40 (2006) 3167-3176

[12] D. Barloková, J. Ilavský, Polish Journal of Environmental Studies 19 (2010) 1117-1122

[13] S.-C. Han, K.-H. Choo, S.-J. Choi, M. M. Benjamin, Journal of Membrane Science 290 (2007) $55-61$

[14] A. G. Tekerlekopoulou, D. V. Vayenas, Desalination 210 (2007) 225-235

[15] E. Okoniewska, J. Lach, M. Kacprzak, E. Neczaj, Desalination 206 (2007) 251-258

[16] A. Omri , M. Benzina, Alexandria Engineering Journal 51 (2012) 343-350

[17] D. Simonsson, Chemical Society Reviews 26 (1997) 181-189.

[18] G. Chen, Separation \&.Purification Technology 38 (2004) 11 - 41

[19] S. Vasudevan, M. A. Oturan, Environmental Chemistry Letters 12 (2014) 97 - 108

[20] M. Ben Sasson, A. Adin, Water Research 44 (2010) 3973 - 3981.

[21] W. P. Cheng, F. H. Chi, Water Research 36 (2002) 4583-4591.

[22] M. Patel, L. Lippincott, X. Meng, Water Research 39 (2005) 2327-2337

[23] M. Pirilä, M. Martikainen, K. Ainassaari, T. Kuokkanen, R. L. Keiski, Journal of Colloid and Interface Science 353 (2011) 257-262

[24] Z. Xu, Q. Li, S. Gao, J. K. Shang, Water Research 44 (2010) 5713-5721 
[25] M. C. Lu, G..D. Roam, J..N. Chen, C. P. Huang, Water Research 30 (1996) 1670-1678

[26] H. K. Shon, S. Vgneswaran, I. S. Kim, J. Cho, G. J. Kim, J. B. Kim, J. H. Kim, Environmental Science and Technology 42 (2007) 1372-1377

[27] S. Vasudevan, J. Lakshmi, G. Sozhan, Desalination 310 (2013) 122-129

[28] P. Westerhoff, Arsenic Removal with Agglomerated Nanoparticle Media, AWWA Research Foundation, Arizona state University, 2006.

[29] H. Jezequel, K. H. Chu, Journal of Environmental Science Health A. 41(2006) 1519-1528.

[30] S. Vasudevan, J. Lakshmi, J. Jayaraj, G. Sozhan, Journal of Hazardous Materials 164 (2009) 1480-1486.

[31] [Y. P. Teoh, M. Ali Khan, T. S. Y. Choong, Chemical. Engineering Journal 217 (2013) 248-255

[32] Y. S. Ho, G. McKay, Process Biochemistry 34 (1999) 451 - 456.

[33] H. M. F. Freundlich, Journal of Physical Chemistry 57 (1906) 385-470.

[34] I. Langmuir, Journal of American Chemical Society. 40 (1918) 1316-1403.

[35] Y. S. Ho, J. F. Porter, G. Mckay, Water Air. Soil Pollution 141 (2002) 1-33.

[36] K. Y. Foo, B. H. Hameed, Chemical Engineering Journal 156 (2010) 2-10.

[37] S. Pan, H. Shen, Q. Xu, J. Luo, M. Hu, Journal of Colloid. Interface Science 365 (2012) 204212.

[38] L. D. Rio, J. Aberg, R. Renner, O. Dahiaten , V. Vedral, Nature 474 (2011) 61-63

[39] C. S. Barrett, T. B. Massalski, Structure of Metals, Third edition, Mc Graw-Hill, NewYork, 1966

[40] S. Debnath, U. C. Ghosh, Desalination 273 (2011) 330-342.

(C) 2014 by the authors; licensee IAPC, Zagreb, Croatia. This article is an open-access article distributed under the terms and conditions of the Creative Commons Attribution license (http://creativecommons.org/licenses/by/4.0/) (cc) Br 